\title{
AGRICULTURA FAMILIAR, PLURIACTIVIDAD Y DESARROLLO RURAL EN EL SUR DE BRASIL*
}

\author{
FLAVIO SACCO DOS ANJOS \\ Universidad Federal de Pelotas, Rio Grande do Sul, Brasil
}

\author{
PALABRAS CLAVE ADICIONALES ADDITIONAL KEYWORDS \\ Estructura social agraria, Sociedad rural, Cambio Agricultural Social Structure, Rural Society, \\ social, Latinoamérica. \\ Social Change, Latin America.
}

RESUMEN. En este artículo se analiza la importancia de la agricultura familiar en el desarrollo de las áreas rurales brasileñas, con especial atención al caso de la Región Sur. Su autor analiza, en primer lugar, las nociones de "agricultura a tiempo parcial" y "pluriactividad", y las conecta con los distintos debates sobre la agricultura. Señala que, mientras el primer concepto puede ser relacionado con la etapa de hegemonía del paradigma de la modernización, el segundo (la pluriactividad) lo está con la etapa actual, dominada por el paradigma de la multifuncionalidad. En segundo lugar, analiza el proceso de modernización que tuvo lugar en Brasil en la década de los 60 , y los efectos de exclusión social que dicho proceso tuvo sobre los pequeños agricultores familiares. En tercer lugar, por último, analiza la relevancia de la agricultura familiar en el actual proceso de desarrollo, y el papel importante que juega la pluriactividad en la dinamización de las zonas rurales.

SUMMARY. In this article, its author analyses the importance of family agriculture for the development of Brazilian rural areas, paying attention to the South Region of Brazil. The autor analyses, firstly, the notions of "part-time agriculture" and "pluriactivity", and linkes each one of them to the different debates on farming sector along time. He shows that whereas the notion of "part-time agriculture" could be linked to the phase where the modernization paradigm was

\footnotetext{
- El presente artículo recoge parte del contenido de la investigación de tesis doctoral desarrollada bajo la dirección de Miren Etxezarreta (Universidad Autónoma de Barcelona) y titulada "Agricultura familiar, pluriactividad y desarrollo rural en Brasil". La lectura de esta tesis doctoral se realizó en el Programa de Doctorado "Agroecología, Sociologia y Estudios Campesinos" de la Universidad de Córdoba, en septiembre dé 2000. Agradezco a Eduardo Moyano sus comentarios a la primera versión de este artículo, especialmente los relativos al debate sobre la pluriactividad en los medios sindicales europeos. E-mail: flaviosa@ufpel.tche.br
}

Revista Internacional de Sociología (RIS)

Tercera Época, nº 28, Enero-Abril, 2001, pp. 173-205. 
dominant, the "pluriactivity" is a notion linked to the current debate on multifunctionality. Secondly, he analyses the process of farming modernization in Brazil in the sixties, and its effects of social exclusion on small farmers. Finally, he analyses the relevance of family agriculture in the present process of rural development in the Southern regions in Brazil, and the importance of pluriactivity on the dynamization of rural areas.

\section{INTRODUCCIÓN}

La importancia económica de Brasil es un hecho indudable, tanto por su potencial exportador (agrícola e industrial), como por haberse convertido en uno de los principales mercados de consumidores, erigiéndose en la novena potencia económica del mundo. Sin embargo, Brasil presenta también otra cara, cual es la de un inmenso territorio dotado de una riqueza natural incomparable, pero plagado de fuertes desequilibrios demográficos (una marcada concentración de la población en la vertiente oriental del territorio brasileño y en las grandes metrópolis), económicos (desigual distribución de la tierra, concentración de rentas en sectores minoritarios de la población, concentración de los factores de producción en determinadas zonas geográficas del país) y sociales (la existencia de un amplio sector de población excluida de los mercados de consumo y sin protección de sus derechos fundamentales al empleo, la salud, la educación o la vivienda).

Recientes estudios de prestigiosos organismos internacionales (PNUD/IPEA, 1996) no han hecho más que confirmar esta situación, mostrando realidades sociales muy distintas y llenas de profundos contrastes. De un lado, la realidad de un Brasil altamente desarrollado, como es el de la Región Sur (formada por los estados federados de Santa Catarina, Rio Grande do Sul y Paraná), cuyos indicadores sociodemográficos dan valores que pueden ser homologables a los de los países desarrollados, y de otro, la realidad de regiones, como las del Norte y Nordeste, donde las condiciones en que vive la población se acercan peligrosamente a situaciones típicas de buena parte de lo que hoy se considera el Cuarto Mundo².

\footnotetext{
${ }^{2}$ Brasil es una república federal de 26 Estados federados. Sólo a efectos geográficos, dichos Estados se agrupan en cinco grandes regiones. La Región Norte comprende los Estados de Amazonas, Pará, Acre, Rondônia, Roraima, Amapá y Tocantins, y es la más grande en extensión, concentrando casi el $45 \%$ de todo el territorio nacional. La Región Nordeste comprende los Estados de Maranhào, Piauí, Ceará, Rio Grande do Norte, Paraiba, Pernambuco, Alagoas, Bahia y Sergipe. La Región Sudeste agrupa a los de Minas Gerais, São Paulo, Rio de Janeiro y Espírito Santo. La Región Centro-Oeste comprende los Estados de Goiás, Mato Grosso, Mato Grosso do Sul y el Distrito Federal (Brasilia, DF). Finalmente, la Región Sur, que es la más pequeña en extensión, comprende los Estados de Rio Grande do Sul, Santa Catarina y Paraná.
} 
En lo que se refiere a la agricultura y la sociedad rural brasileña, fue sobre todo a partir de los años sesenta y setenta cuando se vieron drásticamente transformadas por la influencia de factores tanto externos (la creciente liberalización de los mercados agrícolas), como internos (las políticas de modernización conservadora llevadas a cabo por los gobiernos militares durante la dictadura $)^{3}$. Este proceso de cambio fue reduciendo el carácter agrario y rural de la sociedad brasileña hasta el punto de que, hoy, la agricultura ya no desempeña el protagonismo de tiempos pasados ni la sociedad rural tiene la importancia de antaño. Por ejemplo, si en 1960 el 44,7\% de la población total vivía en las ciudades (70 millones de personas), en 1996 esa proporción se elevaba al 78,4\% (157 millones de personas), según datos del último Censo de población. Asimismo, si hasta mediados de los años cincuenta, dos tercios aproximadamente de las exportaciones totales brasileñas provenían de la agricultura, en los noventa apenas alcanzaban el 3.5\%, habiendo pasado la participación de este sector en el Producto Interior Bruto, de más del $20 \%$ en los años sesenta, al $11 \%$ treinta años más tarde.

Además de esos cambios macroeconómicos, la última década ha sido testigo de otros cambios más específicos cuya repercusión en las dinámicas del mundo rural brasileño está siendo muy importante. Este artículo tratará de uno de esos cambios, cual es el fuerte desarrollo de la pluriactividad en la Región Sur de Brasil, centrándose no sólo en mostrar las nuevas formas que este fenómeno asume, sino también en analizar sus causas explicativas y las condiciones que han permitido su reaparición. Para ello, se dedicará el primer apartado a presentar el debate sobre la "pluriactividad", situándolo en los países en vías de desarrollo y más particularmente en la Región Sur de Brasil, que es el universo empírico en el que se enmarca este trabajo. El segundo apartado analiza el proceso de

\footnotetext{
${ }^{3}$ La dictadura militar en Brasil tuvo una duración de 21 años. Se inició con el golpe militar de 30 de noviembre de 1964 y se prolongó hasta el año 1984, que es cuando empieza el proceso de redemocratización. El periodo que se conoce como modernización conservadora de la agricultura brasileña se desarrolló fundamentalmente entre los años 1965 y 1979, es decir en la primera etapa de la dictadura militar. La expresión en cursiva se refiere a la opción de los Gobiernos militares por la solución tecnológica (cambio en la base de producción con la introducción de los insumos modernos) para la modernización del sector agrario brasileño, manteniendo intacta la estructura fuertemente concentrada de la propiedad fundiaria. Dicho proceso de modernización conservadora respondía también a la concertación de intereses de las clases dominantes de la sociedad brasileña de entonces, entre las que figuraban en lugar destacado, por una parte, la oligarquía rural, preocupada por la efervescencia de los movimientos sociales en el mundo rural, y, por otra, los sectores más modernos del capital industrial de origen urbano, que deseaban ampliar el mercado de consumo para sus producciones, además de inducir el proceso de internacionalización de la economía brasileña. Respecto a este tema véase especialmente Graziano da Silva (1982), Martine (1987), Martine y García (1987), Delgado (1985) y Brum (1987).
} 
RIS

REIISTA INTERNACIONAL DE SOCIOLOGIA

N" 28. Enero-Abril. 2001

FLAVIO SACCO DOS ANJOS

colonización y desarrollo agrícola de la Región Sur, por cuanto que consideramos que en dicho proceso pueden encontrarse algunas claves explicativas de la importancia de la agricultura familiar en esta región. En el tercer apartado se tratará de mostrar que tanto la agricultura familiar, como el mundo rural de esta región brasileña sufrieron cambios de tal envergadura a raíz del proceso de modernización conservadora, que alteró radicalmente el entorno de las familias rurales dificultando su capacidad para reproducirse social y económicamente. De ahí que el último apartado esté dedicado a resaltar la importancia del fenómeno de la pluriactividad en la Región Sur como vía para garantizar la reproducción social de las familias rurales. El artículo concluye con unas reflexiones sobre el futuro del mundo rural brasileño y el papel que la pluriactividad puede jugar en el mismo, a condición de que sea integrado como una estrategia de los poderes públicos que, aprovechando el enorme potencial que encierra la sociedad rural desde el punto de vista demográfico y ecológico, contribuya a mitigar los graves desequilibrios existentes en Brasil.

\section{DE LA AGRICULTURA A TIEMPO PARCIAL A LA PLURIACTIVIDAD}

La premisa fundamental de este artículo es la de que tanto la "agricultura a tiempo parcial" como la "pluriactividad" son fenómenos asociados principalmente, aunque no en exclusiva, a la agricultura familiar, habiendo formado parte de las estrategias de resistencia adoptadas por los grupos domésticos para garantizar la reproducción social de sus miembros. Tales estrategias se han desarrollado mediante la combinación de rentas agrícolas y extra agrícolas a través de actividades realizadas dentro y/o fuera de las propias explotaciones.

Aunque ambos conceptos se refieren a realidades empíricas bastante similares, reflejan no sólo diferencias en términos de su alcance y significado, sino también momentos históricos distintos en el proceso de reflexión sociológica sobre el desarrollo de la agricultura y el campesinado y en las valoraciones que los sociólogos y economistas agrarios han hecho acerca de la naturaleza y funcionalidad de dicho fenómeno ${ }^{4}$. En lo que se refiere a la agricultura a tiempo parcial, se ha destacado su conexión con el proceso de industrialización, en la medida en que amplios sectores del campesinado eran parcialmente incorporados al sector industrial y de servicios trabajando alternativamente en su pequeña explotación o como asalariados en factorías industriales o empresas de servicios de su comarca. Prácticamente en todos los idiomas hay palabras para designar

\footnotetext{
${ }^{4}$ Dicha transición conceptual ha sido magistralmente analizada en un artículo de Füller (1990).
} 
a esta figura ya clásica del paisaje social agrario: campesino obrero, worker peasant, ouvrier-paysan, arbeiterbauer, operai-contadini, camponês operário, etc, destacándose de ella el creciente grado de unificación de los mercados de trabajo urbano y rural (Etxezarreta et al., 1995:78). Aunque existía, y sigue existiendo, alguna controversia respecto a los criterios de definición del concepto de "agricultura a tiempo parcial", lo cierto es que, hasta el final de los años setenta y principios de los ochenta, la mayor parte de los estudios sobre este tema coincidían en considerarlo como un fenómeno de transición (Kolankiewicz, 1979:67) que anunciaba la desaparición definitiva de las explotaciones campesinas en la agricultura contemporánea. Se admitía que se trataba, además, de una manifestación palpable del proceso de éxodo rural y de una de las estrategias de supervivencia utilizadas por las familias campesinas con explotaciones poco modernizadas (Naredo, 1971/1996:180-182). De hecho, hasta finales de los años ochenta, la agricultura a tiempo parcial se consideraba como un factor qüe frenaba el desarrollo capitalista en la agricultura tal como éste había sido previsto por autores clásicos, muchos de ellos de filiación marxista, como Kautsky, que habían acunado lo que podíamos denominar el "paradigma de la proletarización agraria" (Arnalte, 1980:222). Aunque dentro de la tradición marxista, y en un afán de renovación, algunos autores señalaron más tarde la funcionalidad de las explotaciones familiares agrarias para el desarrollo capitalista en algunos sectores como el lácteo (Servolin, 1972) o la horticultura, no se preocuparon de destacar si en tal funcionalidad era necesaria o no la dedicación parcial o completa del titular y su familia. La percepción negativa de la agricultura a tiempo parcial atravesó incluso el mundo sindical y político en la época dorada de la modernización productivista, como lo prueba la animadversion que hacia ella sentían las organizaciones sindicales de mayor influencia en la CEE, como la FNSEA francesa o la DBV alemana, y la escasa atención que se le dedicaba en las instituciones donde se debatían las orientaciones de la política agraria europea, como el COPA (Comité de Organizaciones Profesionales Agrarias) (Lagrave, 1993). La explotación moderna y viable, dirigida por agricultores jóvenes, bien formados técnicamente y con plena dedicación a su profesión, era el modelo a seguir, un modelo en el que la agricultura a tiempo parcial no tenía cabida (Coulomb y Nallet, 1980). Sólo en la periferia de la representación sindical el tema de la agricultura a tiempo parcial cobraba interés y se incluía en las reivindicaciones de organizaciones como el MODEF (Movement pour la Defense de l'Exploitation Familiale) y la CNSTP (Confédération National des Syndicats de Travailleurs Paysannes) franceses o la Confcoltivatori italiana (Moyano, 1988 y 1993).

Más tarde, a mediados de los años ochenta, la utilización del término "pluriactividad" para identificar un fenómeno de naturaleza similar al de la agricultura a tiempo parcial no sólo reflejaba ciertos cambios de perspectiva en los debates sobre el desarrollo agrario y el papel de la agricultura familiar, sino 
que significaba también un drástico cambio de actitud del mundo académico y político respecto a este tema. En los países desarrollados, y especialmente en el ámbito de la Unión Europea, se estaba produciendo un verdadero cambio de paradigma en el tratamiento de los problemas de la agricultura y el mundo rural por parte no sólo de la comunidad científica y la opinión pública, sino también de los responsables políticos y sindicales, tal como se refleja en la literatura económica y sociológica de aquellos años (Füller, 1984 y 1990) y en importantes documentos de la propia Comisión Europea (El Libro Verde de la PAC, en 1985, o El Futuro del Mundo Rural, en 1988). Se estaba realmente pasando del paradigma de la modernización productivista que había guiado el pensamiento agrario y rural desde los años sesenta, a otro (más recientemente denominado paradigma de la multifuncionalidad) en el que se introducen nuevos criterios para valorar los espacios rurales y redefinir la función y el status de la agricultura en ellos: su importancia para el equilibrio territorial y el dinamismo de las zonas rurales, así como para la preservación de los recursos naturales, pasarían a ocupar el primer plano en la definición de las nuevas políticas agrarias (Hervieu, 1996; Delorme y Le Theule, 1996; Moyano, 1997).

En ese contexto de cambio, agudizado por el creciente abandono de amplias zonas rurales o por el deterioro ambiental provocado por los modelos intensivos e hiperespecializados de agricultura, se producirá una profunda revisión del tratamiento recibido hasta entonces por la agricultura a tiempo parcial, reflejando el nuevo término de "pluriactividad" dicho giro intelectual y político. Desde entonces, no sólo se reconocerá como un hecho indudable de la agricultura contemporánea la combinación de actividades y rentas (dentro y fuera de la propia explotación) por parte de los agricultores, sino que pasará a ser admitido ese fenómeno como un factor positivo para el desarrollo de las zonas rurales.

La casi totalidad de los esfuerzos académicos por analizar el fenómeno de la agricultura a tiempo parcial, primero, y de la pluriactividad, después, se produjo en los países desarrollados. Aunque hubo algunos estudios pioneros en África y Latinoamérica (véase Christodoulou y Okafor citados en Cavazzani, 1982), pocas investigaciones enfocaron la cuestión desde el prisma de los países en vías de desarrollo. Es tan sólo a partir de la segunda mitad de los años ochenta y principios de los noventa que empieza a surgir un mayor número de investigaciones con el objetivo de captar la dinámica de los procesos que tienen lugar en la sociedad rural sin centrarse sólo y exclusivamente en factores relacionados con la agricultura. Estudios como los de Klein (1992) y Weller (1997) no sólo buscaban acercarse al objetivo de estimar la magnitud del empleo rural no agrario en Latinoamérica, sino también tipificarlo y demostrar la necesidad de potenciarlo, ya fuese como forma de ocupar la mano de obra familiar, ya fuese como mecanismo para aumentar la renta familiar. Ambos autores mostraban que, al igual que ocurre en los países centrales, la capacidad 


\begin{tabular}{|c|c|}
\hline & RETISTA INTERN_CLONAL DE SOCIOLOGi. \\
\hline AGRICULTURA FAMILLAK, PLURACTITIDAD Y DES SRROLLO... & N" 20. Enero-dbril. 200 \\
\hline
\end{tabular}

de la agricultura para absorber la mano de obra en las comunidades rurales de los países periféricos era cada vez menor, cobrando importancia creciente otras actividades no agrarias. Los llamados ingresos extra-agrarios (Piñeiro, 1985; Palau y Heikel, 1987) asumirán en estos trabajos un papel determinante para comprender un proceso que comenzará a incidir de modo generalizado en todo el continente latinoamericano (Ortega, 1992; De Janvry y cols., 1989). Aunque el proceso sigue pautas y condiciones diferentes en los distintos países, de acuerdo con el respectivo nivel de desarrollo de las fuerzas productivas, el rasgo común en todos ellos es el hecho de que el empleo rural no agrícola crece más rápidamente que el agrícola (Kay, 1995).

Respecto a Brasil, el estudio sobre la agricultura a tiempo parcial y la pluriactividad ha empezado muy recientemente, y la mayor parte de las investigaciones se centran en la Región Sur, por ser ésta una región donde dicho fenómeno adquiere mayor importancia. Antes de medir su importancia en términos económicos y sociales, y con la finalidad de desentrañar los elementos que expliquen las características que asume el fenómeno de la pluriactividad en la región Sur, dedicaremos el próximo apartado a analizar algunos aspectos del proceso de formación de su estructura social.

\section{COLONIZACIÓN Y AGRICULTURA FAMILIAR EN LA REGIÓN SUR}

Integrada por los estados federados de Rio Grande do Sul, Santa Catarina y Paraná, la Región Sur es la segunda región más importante de Brasil en términos económicos, justo detrás de la Región Sudeste, liderada por el estado de São Paulo. El último Censo de Población realizado el año 1991 (IBGE, 1994) registró una población total de 22,13 millones de habitantes en la Región Sur, siendo Rio Grande do Sul el estado más poblado (9,14 millones), seguido de Paraná (8,45 millones) y Santa Catarina (4,54 millones). La misma fuente indica que tan sólo el 25,9\% de la población de la Región Sur (5,73 millones) residía a principios de los años noventa en el ámbito rural. La importancia económica de la Región Sur se refleja en el hecho de que, ocupando el $6,7 \%$ de la superficie total del territorio brasileño (una superficie equivalente al área total de la Península Ibérica), era por esas fechas responsable de casi el $19 \%$ del PIB de Brasil y del $26 \%$ de las exportaciones totales del país (ver mapa adjunto).

La privilegiada situación de la Región Sur respecto a las demás regiones brasileñas, no es sólo consecuencia de sus mejores y más eficientes estructuras productivas, sino resultante también de las singulares características que tuvo el proceso de colonización en dicha región a lo largo de la segunda mitad del siglo XIX. Para el hilo argumental del presente artículo, interesa destacar dos grandes efectos del proceso de colonización: contribuir a la constitución en esta Región del más importante sector de agricultores familiares de Brasil y asentar las 
RIS

RETISTA INTERNACIONAL DE SOCIOLOGIA

N" 28. Enero-Abril. 2001

FLAVIO SACCO DOS ANJOS

Sudamérica y Brasil (Grandes Regiones y Estados Federativos)

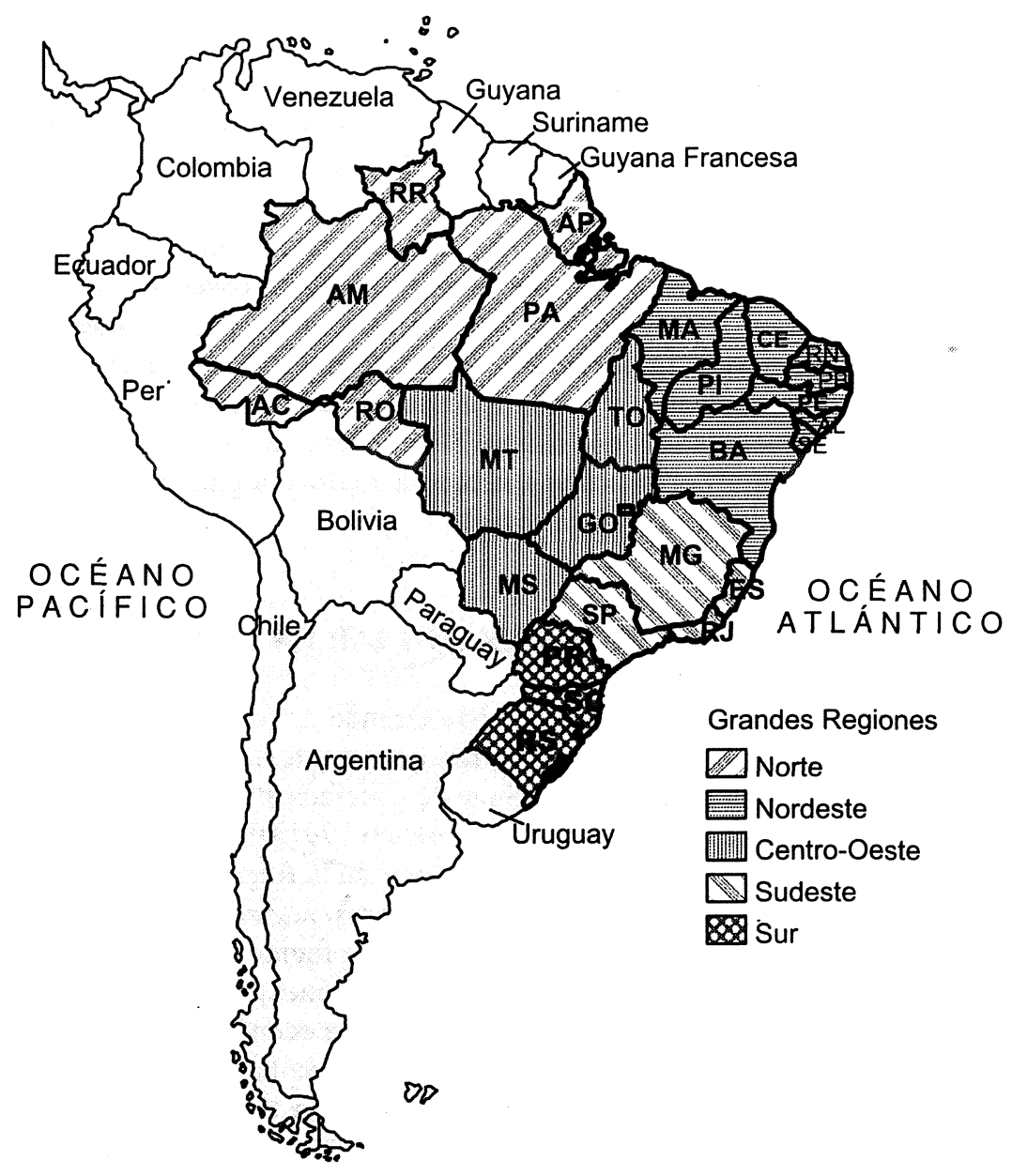

AC: Acre, AM: Amazonas, RR: Roraima, AP: Amapá, PA: Pará, Ro: Rondônia, MA: Maranhao, Pl, Piauí, CE, Ceará, RN, Rio grande do Norte, PB, Paraíba, PE, Pernambuco, AL: Alagoas, SE: Sergipe, BA, Bahia; MT: Mato Grosso, To: Tocantins, GO, Goiás, MS, Mato Grosso do Sul; MG, Minas Gerais, ES, Espírito Santo, RJ, Rio de Janeiro, SP: Sao Paulo; PR: Paraná, SC: Santa Catarina; RS: Rio Grande do Sul. 
bases para el proceso de industrialización regional. Tales efectos estuvieron ligados estrechamente al protagonismo adquirido por los colonos provenientes de Europa (alemanes, polacos y noritalianos), unos colonos que incorporaron a la sociedad de esta región brasileña un ethos singular (Gaiger, 1994; Tedesco, 1999) que plasmaba los rasgos típicos del campesinado centroeuropeo, principalmente su dinamismo para la diversificación económica de las unidades familiares de producción.

Los analistas suelen estar de acuerdo en el hecho de que las raíces de la industrialización de las zonas septentrionales de Rio Grande do Sul y de la vertiente oriental de Santa Catarina se encuentran precisamente asociadas al florecimiento de esta "agricultura colonial" y al proceso de acumulación de capital allí resultante, un fenómeno en el que tuvo una importancia decisiva el conocimiento técnico de los inmigrantes. A ello habría que añadir la intensa articulación que se fue desarrollando en esas zonas entre ciertas ramas de actividad industrial y las estrategias seguidas por las familias rurales para garantizar su reproducción, dando a la dinámica social y económica de la región Sur un rasgo diferenciador respecto de otras regiones brasileñas ${ }^{5}$. Estos rasgos singulares del modelo de desarrollo industrial de la Región Sur de Brasil han sido analizados por autores como Ignacy Sachs (1990) destacando precisamente su carácter excepcional respecto al conjunto del proceso colonizador: "Las experiencias recientes de colonización de tierras vírgenes (en Brasil) han sido decepcionantes. Sin embargo, en los estados del Sur surgió en el pasado un modelo de desarrollo caracterizado por una configuración rural-urbana equilibrada, una agricultura campesina exitosa y la instalación de empresas industriales de pequeña y mediana escala" (Sachs, 1990: 252-253).

Aunque no estaban precisamente centrados en el tema de la agricultura a tiempo parcial, los estudios pioneros de Seyferth $(1974,1985$ y 1987) tuvieron el mérito de poner de manifiesto las peculiaridades de una categoría social hasta entonces ignorada en los trabajos sobre el medio rural sureño. Su referencia al llamado colono operario del Valle del Itajaí y del Litoral Norte en Santa Catarina o del Valle del Sinos y Caí en Rio Grande do Sul mostraba la versión brasileña del worker-peasant que aparece en muchos estudios europeos, como los desarrollados por Franklin (1969) en su obra seminal. Posteriormente, ya en los noventa, surgieron los primeros estudios específicos sobre la agricultura a tiempo parcial en la Región Sur de Brasil, como los de Schneider sobre

\footnotetext{
${ }^{5}$ En este sentido, pueden tomarse como ejemplos de este modelo de articulación entre familias campesinas e industria (al que algunos autores denominan modelo NEC comparándolo con el de la Terza Italia) los casos del sector cuero-calzado en Rio Grande do Sul (Schneider, 1999 y 1999a) y de otros importantes sectores industriales de Santa Catarina (como el textil-confección y el metalúrgico-mecánico) (véase especialmente Raud, 1995a, 1995b y 1999).
} 


\section{RIS}

Rio Grande do Sul (Schneider, 1994 y 1995) y Sacco dos Anjos sobre Santa Catarina (Sacco dos Anjos, 1994, 1995a, 1995b y 1995c), en los que se analiza el fenómeno de la combinación alternativa de rentas y actividades agrarias y no agrarias como estrategia de adaptación y resistencia de los agricultores con pequeñas explotaciones de tipo familiar.

La posterior incorporación de la noción de "pluriactividad" a la literatura sociológica y económica brasileña de los años noventa coincidirá con nuevos trabajos que han tratado de analizar otras dimensiones del fenómeno más allá de su asociación con los procesos de industrialización regional. En estos trabajos (Sacco dos Anjos, 1994 y 1995a) se demuestra que la pluriactividad no es simplemente una estrategia de adaptación que se da de forma exclusiva en las familias campesinas con explotaciones no competitivas desde el punto de vista técnico y económico, sino que también tiene incidencia en los casos de explotaciones familiares modernizadas. En estas explotaciones altamente tecnificadas, las familias no sólo buscan con dicha estrategia ocupar la mano de obra excedente que ha sido desplazada por la creciente tecnificación de las labores agrícolas y aumentar la renta total, sino también diversificar el uso de los recursos naturales y productivos disponibles. En efecto, a través de un estudio desarrollado en el estado de Rio Grande do Sul por la agencia pública de extensión rural (Emater-RS) a comienzos de los años noventa (Brumer, 1999) y con base en informaciones recogidas en un total de 3.584 explotaciones agrarias de este estado federado y de un total de 15.277 personas encuestadas, se llegó a conclusiones muy importantes, aunque centradas sólo en el examen de la cuestión del tiempo de trabajo. De hecho, tal como señala Brumer (op.cit.: 237), del total de la población activa residente en el medio rural de Río Grande do Sul (dedicada al ejercicio de actividades agrícolas y extra-agrícolas), trabajaba en su propia explotación agraria el $72,1 \%$ a "tiempo completo" y el $15,5 \%$ a "tiempo parcial", mientras que la proporción de personas que trabajaban fuera de su explotación era equivalente a un $12,4 \%$. Resulta, por tanto, que las personas dedicadas parcialmente a la explotación familiar y las que trabajaban exclusivamente fuera de ella concentraban casi el $28 \%$ de la población activa en el medio rural de Río Grande do Sul. Además del trabajo antes mencionado, merece la pena destacar el denominado "Projeto Rurbano", iniciado en 1997, que hoy por hoy constituye el mayor esfuerzo por cuantificar el fenómeno de la pluriactividad en Brasil. Este proyecto de investigación enmarca dicho fenómeno dentro de las grandes transformaciones que viene experimentando la sociedad rural brasileña, destacando principalmente los cambios producidos en la estructura ocupacional y en el mercado laboral, así como el creciente protagonismo de las actividades y ocupaciones extra agrícolas ${ }^{6}$ en los procesos de reproducción social de las familias rurales.

No obstante, y antes de analizar con más detalle el fenómeno de la pluriactividad en la Región Sur, dedicaremos el próximo apartado a estudiar la estructura 
agraria de esta Región y la evolución que ha seguido a la luz de los cambios introducidos por la modernización conservadora de la agricultura brasileña. En concreto se analizará el entorno económico de las explotaciones familiares de la Región Sur, y los efectos que el proceso modernizador tuvo en las estructuras organizativas de estas explotaciones y en sus respectivas estrategias de subsistencia y adaptación.

\section{MODERNIZACIÓN AGRARIA Y EXCLUSIÓN SOCIAL EN LA REGIÓN SUR}

La Región Sur es la principal zona agrícola de Brasil y su contribución se centra fundamentalmente en los cultivos de ciclo anual, representando alrededor del $40 \%$ del área total de estos cultivos en el conjunto del país: trigo (92\%), tabaco $(86,5 \%)$, soja $(51 \%)$, maíz $(46,3 \%)$ y algodón $(37,4 \%)$. Su protagonismo es igualmente acentuado en los cultivos leñosos de clima templado, como manzana $(9.7,6 \%)$, pera $(63,2 \%)$, uva $(73,6 \%)$ y melocotón $(81,1 \%)$ (IBGE, 1995). En lo referente a la producción animal, la ganadería porcina y la avicultura son dos sectores en los que la posición de la Región Sur es preponderante en el conjunto del país. En el primer caso, la participación de la Región Sur en la cabaña porcina brasileña es de casi el $34 \%$, mientras que en la avicultura alcanza cerca del $47 \%$; en el sector avícola, y gracias precisamente a la producción sureña, Brasil se sitúa en el grupo de cabeza de los países mayores exportadores mundiales de carne de pollo, siendo la integración vertical el sistema de relación que predomina entre los grandes complejos agroindustriales y los productores con explotaciones ganaderas de tipo familiar, habiendo generado incluso nuevas formas de cooperación, como los "condominios" agrarios (Sacco dos Anjos y Moyano, 2001).

Según los criterios adoptados en el Informe FAO/INCRA (1996) para medir la importancia económica de la agricultura familiar, las explotaciones de este

\footnotetext{
${ }^{6}$ En la Región Centro-Oeste, el Proyecto Rurbano incluye tan solo Brasilia (DF) como objeto de investigación, mientras que en el Nordeste del país se estudian los estados de Piauí, Rio Grande do Norte, Alagoas y Bahia. La Región Sudeste incluye São Paulo, Minas Gerais y Rio de Janeiro. En la Región Sur, el estudio abarca los tres estados (Rio Grande do Sul, Santa Catarina y Paraná). La financiación del Proyecto Rurbano proviene de la fundación FAPESP (Fundación de Apoyo a la Investigación del estado de São Paulo), de la Secretaria de Desarrollo Rural del Ministerio de Agricultura brasileño y, más recientemente, del CNPq (Consejo Nacional de Investigación y Desarrollo Tecnológico). Respecto a las características del proyecto y los materiales obtenidos, puede consultarse la página: http://www.eco.unicamp.br/projetos.
} 
R I S

RETISTA INTERNACIONAL DE SOCIOLOGIA

N" 28. Enero-Abril. 2001

FLAVIO SACCO DOS ANJOS

tipo ocupan el equivalente al 22,1\% del área agrícola total de Brasil, estando el $21,1 \%$ de ellas ubicado en la Región Sur. De acuerdo con los datos del último Censo agrario (IBGE, 1997; 1998), las explotaciones agrarias de superficie inferior a las 50 hectáreas - entre las que se incluiría la mayor parte de las consideradas como familiares- comprenden aproximadamente el 86,5\% del total de explotaciones existentes en la Región Sur de Brasil (equivalente a algo más de un millón de explotaciones), absorbiendo tan sólo el 28,0\% del área agrícola total (cerca de 44,4 millones de hectáreas). Asimismo, estas explotaciones de tipo familiar son responsables de alrededor del 53,0\% del valor bruto de la producción final agraria de esa región y del $62,5 \%$ y $46,7 \%$ del valor bruto de la producción animal y vegetal, respectivamente. Hay que subrayar que esa participación se da en un contexto de total inexistencia de una política agraria específicamente orientada a apoyar al sector de agricultura familiar, como lo prueba el hecho de que este sector apenas pudo beneficiarse de una tercera parte del valor total del crédito agrícola concedido en la Región Sur durante el año agrícola 1995-96.

La forma adoptada por la modernización agrícola en Brasil ha sido, tal como se ha señalado anteriormente, calificada por diversos autores como "modernización conservadora" por haber contribuido a mantener un alto nivel de concentración de la estructura fundiaria en ausencia de medidas de redistribución de la propiedad de la tierra (Guimarães, 1979; Graziano da Silva, 1982 y 1983; Martine, 1987). Además de provocar un éxodo rural sin precedentes, así como de intensificar la concentración de la tierra, de faworecer a los grandes productores y a los cultivos de exportación, de impulsar la transferencia de renta y recursos al sector urbano-industrial y de favorecer la concentración urbana y los problemas de ella derivados (elevada congestión de los núcleos urbanos, marginación social, desempleo, etc.), otros aspectos asociados con este proceso de modernización conservadora de la agricultura han comenzado a ponerse de manifiesto gracias a los estudios que recientemente se han realizado sobre la estructura agraria brasileña. La novedad de estos estudios radica en relacionar tales cambios con el proceso general de transformación que experimenta la sociedad brasileña en su conjunto. De hecho se viene constatando los enormes impactos que dicho proceso ha inducido en el sentido de simultáneamente provocar el envejecimiento de la población rural (Schneider, 1994; Camarano y Abramovay, 1997; Abramovay et al., 1997; Brumer, 1999, y Sacco dos Anjos, 2000).

Como es conocido, el auge de la modernización agrícola brasileña coincidió con el período comprendido entre 1965 y 1979, en el que, bajo la égida de los gobiernos militares y mediante un ambicioso programa de crédito agrícola fuertemente subvencionado, hubo un intenso proceso de mecanización e incorporación de insumos modernos. Simultáneamente, se amplió la base agraria de producción mediante la incorporación de nuevas tierras de la llamada "frontera agrícola" en las regiones Centro-Oeste ${ }^{7}$ y Norte de Brasil. Dicho 
proceso fue intensificado sobre todo a raíz del interés del gran capital en la valorización de los activos (territorialización del capital) y de los generosos subsidios ofrecidos por los Gobiernos de la Dictadura militar para la ocupación de nuevas tierras. Pero hay que subrayar que el incremento de la producción agrícola brasileña resultó del efecto conjunto de la extensificación de la superficie agrícola y de la intensificación generada por la introducción masiva de insumos modernos en el contexto de creciente industrialización de la agricultura (Graziano da Silva, 1982: 123-124).

Ambos caminos, sin embargo, conllevaron ciclos de reconcentración de la posesión de la tierra en Brasil. En este sentido, y tan sólo en el período comprendido entre 1940 y 1985, mientras que el número total de explotaciones se incrementó el $206 \%$, pasando de 1.904 .508 a 5.834 .779 explotaciones, el aumento del área agrícola total fue igualmente espectacular, pasando de 197.720.247 hectáreas a 376.286.577. Pero en el año 1985, mientras que "en el Sur de Brasil las explotaciones con menos de 10 hectáreas absorbían el $94,1 \%$ del total de las explotaciones y concentraban el $39,1 \%$ del área total, en la Región Centro Oeste del país representaban el 62,3\% de las explotaciones aunque ocupando la escasa proporción del $4,9 \%$ del área agrícola total. En esta región de Brasil, las explotaciones con más de mil hectáreas concentraban el 69,3\% de la tierra existente (Oliveira, 1994: 56-57).

Con la instauración de la democracia a mediados de los años ochenta, el proceso de modernización no se detuvo, sino que continuó avanzando, aunque modificando algunas de sus orientaciones iniciales y cambiando sensiblemente la naturaleza de la intervención estatal. De hecho, desde finales de los años ochenta, como señala Walter Belik (1997), se instaura en Brasil un nuevo patrón de intervención estatal en la agricultura, que implicó, entre otras cosas, la transferencia a los mercados de la tarea de regular los precios agrícolas y una pronunciada retirada de los mecanismos de protección del sector agrario en un contexto de creciente apertura comercial y de liberalización de las importaciones de productos agrícolas. El resultado concreto e inmediato de este nuevo modelo de intervención ha sido una sensible disminución del área cultivada en los grandes cultivos (especialmente arroz, maíz, trigo, algodón), un descenso de las

\footnotetext{
${ }^{7}$ Según las estimaciones de Ryff (1988:101), en los años 70 fueron incorporados cerca de 15 millones de hectáreas de nuevas tierras de cultivo en Brasil, siendo más de 4 millones tan sólo en la Región Centro Oeste. El autor señala la existencia de cinco grandes factores para ello: el incremento exponencial del crédito agrícola subsidiado, los incentivos hacia el objetivo de autosuficiencia en la producción de trigo, la demanda creciente de caña de azúcar provocada por la aparición del "Programa Nacional de Alcohol", la elevación de los precios internacionales de los productos agrícolas y el relativo grado de eficiencia de la política de precios mínimos llevada a cabo en esa década.
} 
rentas agrarias y una pronunciada desactivación de las explotaciones agrarias, sobre todo en el ámbito de la agricultura empresarial, a causa del menor atractivo de la agricultura como objeto de inversión de capital. Paradójicamente, el descenso del área cultivada - y ello ha sido particularmente claro en el caso de la Región Sur - ha coincidido con el incremento en la producción agrícola, especialmente en el caso de los llamados cultivos dinámicos (destinados a la exportación y/o sustitución de importaciones). Los datos presentados en la tabla 1 plasman indiscutiblemente dicha tendencia, que puede ser evaluada desde el punto de vista global de la Región Sur o desde el prisma de cada uno de los Estados que la integran.

La primera de las tres grandes columnas se refiere a la disponibilidad de área para cultivos anuales o permanentes, y revela que hubo una reducción absoluta para la Región Sur del orden de 2.200 .000 hectáreas, lo que equivale a un $15,3 \%$. Es en la segunda columna donde quedan reflejados los cambios a que nos estamos refiriendo. Arroz, maiz, soja y trigo componen el conjunto que llamamos de "grandes cultivos" (GC), responsables, el año 1995, de cerca del $83 \%$ de todo el área cosechada en el sector agrario sureño y de, respectivamente, el $54,9 \%$ y el $33,5 \%$ del valor bruto de la producción vegetal y del valor agrícola

Tabla 1.

Evolución del área de labranza, de la superficie agricola total de arroz, trigo, maiz y soja (ATMS), y de la producción en toneladas entre los años 1985 y 1995 de los estados de Rio Grande do Sul (RS), Santa Catarina (SC) y Paraná (P), y de la Región Sur en su conjunto.

\begin{tabular}{|c|c|c|c|c|c|c|}
\hline \multirow[b]{3}{*}{ Unidad } & \multicolumn{6}{|c|}{ a) en números absolutos (en hectáreas) } \\
\hline & \multicolumn{2}{|c|}{ Área de Labranza (has) } & \multicolumn{2}{|c|}{ Área de Cultivos (ATMS) (has) } & \multicolumn{2}{|c|}{ ) Producción (toneladas) } \\
\hline & 1985 & 1995 & 1985 & 1995 & 1985 & 1995 \\
\hline RS & 6.592 .085 & 5.635 .362 & 6.787 .836 & 4.984 .251 & 12.581 .186 & 12.241 .865 \\
\hline $\mathrm{SC}$ & 1.868 .832 & 1.570 .420 & 1.374 .508 & 1.034 .087 & 2.790 .329 & 3.211 .446 \\
\hline PR & 6.062 .559 & 5.100 .509 & 5.416 .129 & 4.805 .425 & 10.859 .641 & 13.635 .961 \\
\hline Región Sur & 14.523 .476 & 12.306 .291 & 13.578 .473 & 10.823 .763 & 26.231 .156 & 29.089 .272 \\
\hline \multicolumn{7}{|c|}{ b) en números relativos (en \%) } \\
\hline $\mathrm{RS}$ & 100,0 & 85,5 & 100,0 & 73,4 & 100,0 & 97,3 \\
\hline $\mathrm{SC}$ & 100,0 & 84,0 & 100,0 & 75,2 & 100,0 & 115,1 \\
\hline PR & 100,0 & 84,1 & 100,0 & 88,7 & 100,0 & 126,0 \\
\hline Región Sur & 100,0 & 84,7 & 100,0 & 79,7 & 100,0 & 111,0 \\
\hline
\end{tabular}

Fuente: Censo Agropecuario 1995-1996 (IBGE, 1997 y 1998). 
bruto total de la producción regional (equivalente a 14.973 millones de reales o a aproximadamente 15 mil millones de dólares). Los datos permiten ver que, entre 1985 y 1995 , el área cosechada de los GC supuso un descenso absoluto de 2.754.710 hectáreas $(20,3 \%)$, al tiempo que se observa que la producción conjunta ha crecido el equivalente a 2.858 .116 toneladas $(11 \%)$.

La explicación de este hecho reside en que los años noventa han sido testigos de un incremento general de la productividad agrícola. El principal impulsor de dicha dinámica ha sido el efecto combinado del descenso general de los precios agrícolas en los mercados nacional e internacionales y la elevación de los costes de producción. En este sentido, la principal implicación de tal tendencia ha consistido en la destrucción de puestos de trabajo en la agricultura. En efecto, tal como muestran los datos de la tabla 2, entre 1985 y 1995 hubo una reducción de

Tabla 2.

Personal ocupado (titular y ayudas familiares; empleados permanentes y eventuales, aparceros y otros) en 1970, 1980, 1985 y 1995 en los Estados de la Región Sur de Brasil.

\begin{tabular}{|c|c|c|c|c|c|c|c|c|}
\hline \multirow{2}{*}{$\begin{array}{l}\text { Categoría } \\
\text { ocupacional }\end{array}$} & \multicolumn{2}{|c|}{1970} & \multicolumn{2}{|c|}{1980} & \multicolumn{2}{|c|}{1985} & \multicolumn{2}{|c|}{1995} \\
\hline & Número & $\%$ & Número & $\%$ & Número & $\%$ & Nímero & $\%$ \\
\hline \multicolumn{9}{|l|}{ Rio Grande do Sul } \\
\hline Titular y ayudas fam. & 1.314 .904 & 90,9 & 1.502 .023 & 86,0 & 1.492 .886 & 85,4 & 1.180 .224 & 85,7 \\
\hline Emp. Permanentes & 63.573 & 4,4 & 110.030 & 6,3 & 122.640 & 7,0 & 105.738 & 7,7 \\
\hline Emp. Temporeros & 49.468 & 3,4 & 113.879 & 6,5 & 106.365 & 6,1 & 64.605 & 4,7 \\
\hline Aparceros & 12.862 & 0,9 & 14.217 & 0,8 & 11.418 & 0,7 & 13.559 & 1,0 \\
\hline Otras categorias & 6.006 & 0,4 & 6.081 & 0,4 & 14.623 & 0,8 & 12.89 .6 & 0,9 \\
\hline Total & 1.446 .813 & 100,0 & 1.746 .230 & 100,0 & 1.747 .932 & 100,0 & 1.377 .022 & 100,0 \\
\hline \multicolumn{9}{|l|}{ Santa Catarina } \\
\hline Titular y ayudas fam. & 708.436 & 92,8 & 741.398 & 88,6 & 773.675 & 87,2 & 618.748 & 86,1 \\
\hline Emp. Permanentes & 17.870 & 2,3 & 35.830 & 4,3 & 42.381 & 4,8 & 42.505 & 5,9 \\
\hline Emp. Temporeros & 30.483 & 4,0 & 53.345 & 6,4 & 61.893 & 7,0 & 46.988 & 6,5 \\
\hline Aparceros & 4.118 & 0,5 & 4.004 & 0,5 & 3.725 & 0,4 & 5.017 & 0,7 \\
\hline Otras categorías & 2.594 & 0,4 & 2.178 & 0,2 & 5.613 & 0,6 & 5.436 & 0,8 \\
\hline Total & 763.501 & 100,0 & 836.755 & 100,0 & 887.287 & 100,0 & 718.694 & 100,0 \\
\hline \multicolumn{9}{|l|}{ Paraná } \\
\hline Titular y ayudas fam. & 1.696 .284 & 85,6 & 1.369 .230 & 75,7 & 1.374 .983 & 74,1 & 983.329 & 76,4 \\
\hline Emp. Permanentes & 132.073 & 6,7 & 193.185 & 10,7 & 167.798 & 9,1 & 143.124 & 11,1 \\
\hline Emp. Temporeros & 119.126 & 6,0 & 190.483 & 10,5 & 254.404 & 13,7 & 118.699 & 9,2 \\
\hline Aparceros & 24.607 & 1,2 & 50.093 & 2,8 & 37.501 & 2,0 & 18.363 & 1,4 \\
\hline Otras categorías & 9.381 & 0,5 & 4.835 & 0,3 & 20.377 & 1,1 & 24.117 & 1,9 \\
\hline Total & 1.981 .471 & 100,0 & 1.807 .826 & 100,0 & 1.855 .063 & 100,0 & 1.287 .632 & 100,0 \\
\hline
\end{tabular}

Fuente: Elaboración propia a partir de Deser (1992) y Censo Agropecuario 1995/1996 (IBGE, 1997; 1998). 
RIS

RETISTA INTERNACIONAL DE SOCIOLOGIA

N" 28. Enero-Abril. 2001

FLAFIO SACCO DOS ANJOS

casi el $25 \%$ del conjunto de personas ocupadas en la agricultura, disminuyendo en términos absolutos en más de 1,1 millones de personas en la Región Sur.

Este descenso afectó tanto a la categoría de los asalariados, como a los titulares de pequeñas explotaciones y sus ayudas familiares, hecho explicado, de un lado, por la ya mencionada desactivación de la agricultura empresarial -que provocó importantes despidos de la mano de obra ocupada en las grandes explotaciones- $\mathrm{y}$, de otro, por la crisis de capitalización que sufrieron las explotaciones familiares incorporadas al proceso de modernización y sumidas más tarde en una espiral de endeudamiento.

Los años 90, tal como queda reflejado en el Gráfico 1, han estado marcados por el pronunciado desfase entre las rentas agrícolas y no agrícolas. Tanto la creciente apertura comercial y liberalización de las importaciones, como la drástica reducción de los subsidios a la agricultura, actuaron en el sentido de consolidar dicho proceso. A ello habría que añadir como factor adicional de desajuste la integración regional protagonizada tras la creación del Mercado Común del Cono Sur (Mercosur), que, al exponer al sector agrario brasileño a la competencia comercial, sobre todo con los productores de Argentina y Uruguay, acentuó con ello la presión sobre el descenso general de las rentas agrarias. El Mercosur afectó negativamente sobre todo a la Región Sur y de modo particular a los productores familiares sureños cuyos cultivos y actividades agrarias se identifican con los desarrollados en los países vecinos que compiten por un mismo mercado. En el año 1997, tal como demuestra el Gráfico 1, la diferencia entre rentas agrícolas y no agrícolas se hizo más reducida aún que

Gráfico 1.

Evolución de la renta total de las personas residentes en el medio rural de Brasil según su procedencia agrícola o no agrícola entre los años 1992 y 1997.

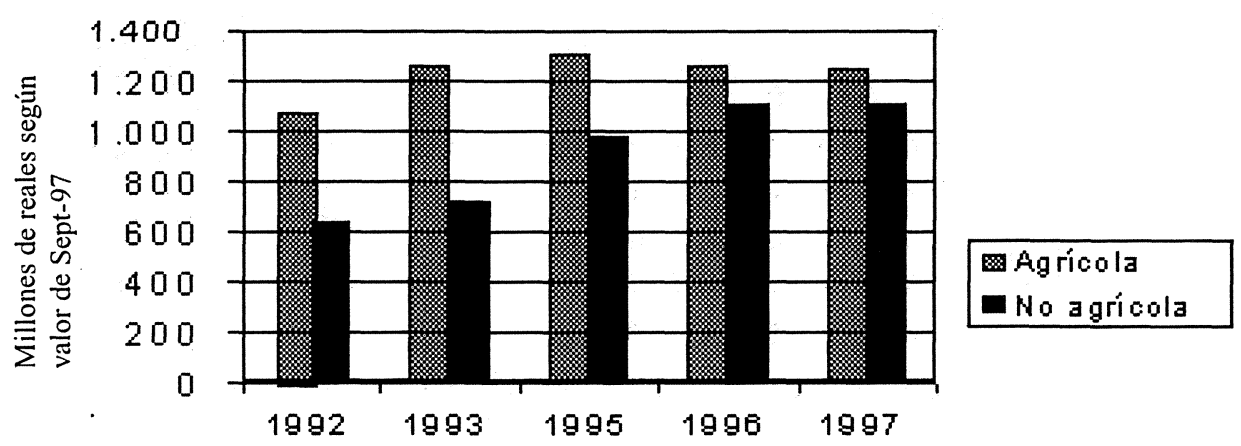

Fuente: Proyecto Rurbano (Estadisticas Especiales); se utiliza el INPC (Indice Nacional de Precios al Consumidor) como deflactor. 
en años anteriores, siguiendo una tendencia bastante regular de reducción de diferencias.

\section{LA PLURIACTIVIDAD EN LA REGIÓN SUR}

La pluriactividad de las familiares rurales en la Región Sur y el incremento de la población rural ocupada en actividades no agrícolas representan dos fenómenos convergentes que se refuerzan mútuamente. La pluriactividad se presenta vinculada a una serie de factores a los que hicimos mención anteriormente. De un lado, a su estrecha asociación con el proceso de industrialización regional y con la creciente unificación del mercado de trabajo urbano y rural, y, de otro, a los mecanismos de adaptación de las explotaciones familiares ante las dificultades de reproducirse en el marco estricto y exclusivo de la actividad agrícola y de las rentas que ésta aporta. El escenario recesivo impuesto sobre la agricultura brasileña desde finales de los años ochenta por el nuevo modelo de intervención estatal, ha tenido importantes efectos restrictivos en lo que afecta a su capacidad de ocupación de la mano de obra y de generación de rentas de origen agrícola. El aumento de productividad de las explotaciones agrarias, el descenso de los precios de los productos agrícolas y la liberalización de los mercados impuesta bajo los programas de ajuste estructural y del proceso de integración regional (Mercosur), son elementos que han actuado también en el sentido de reforzar dicha dinámica, favoreciendo el desarrollo de la pluriactividad como vía complementaria por parte de las familias rurales. Desafortunadamente, las estimaciones respecto a la incidencia del fenómeno de la pluriactividad varían de unos estudios a otros, debido a la insuficiencia de los datos y a las diferentes metodologías empleadas. Pero más allá de estas limitaciones, la mayor parte de tales estudios ponen de manifiesto la importancia creciente del empleo no agrícola en el conjunto de la población rural, siendo éste un indicador bastante significativo de dicho fenómeno. Los datos que presentamos a continuación son bastante elocuentes al respecto, mostrando que el mundo rural de la Región Sur se ha insertado en una dinámica social y económica que supera los límites estrictos de la agricultura. En este sentido, los datos de la tabla 3 indican la evolución de las distintas categorías ocupacionales de la población agrícola en esta región, mientras que la tabla 4 muestra la evolución de estos colectivos en cada uno de los tres estados que la integran (Rio Grande do Sul, Santa Catarina y Paraná), medida en términos de sus tasas de incremento y de los respectivos niveles de significación estadística en el período de tiempo comprendido entre los años 1981 y 1997.

Como se puede constatar en la tabla 4, es sobre todo en los años noventa cuando se evidencia un pronunciado desfase entre los ritmos de ocupación en el ámbito de las actividades agrícolas y no agrícolas en el conjunto de la Región 
Tabla 3.

Evolución de la población de la Región Sur con edad igual o superior a los diez años, en 1981, 1992 y 1997, según hábitat de residencia y situación ocupacional (en miles de personas).

\begin{tabular}{|c|c|c|c|c|}
\hline \multicolumn{2}{|c|}{ Hábitat de residencia / Situación ocupacional } & 1981 & 1992 & 1997 \\
\hline \multicolumn{2}{|l|}{ Urbana } & $9.247,1$ & $13.366,7$ & $15.067,8$ \\
\hline \multicolumn{2}{|l|}{ Rural } & $5.495,8$ & $4.431,0$ & $4.176,9$ \\
\hline \multirow[t]{2}{*}{ Población rural ocupada } & Agrícola & $3.043,5$ & $2.569,1$ & $2.066,6$ \\
\hline & No agrícola & 610,7 & 638,8 & 763,5 \\
\hline \multirow[t]{3}{*}{ Población rural no ocupada } & Buscando empleo & 16,9 & 32,9 & 62,5 \\
\hline & Jubilados/pensionistas & 255,0 & 252,1 & 335,8 \\
\hline & Otros & $1.569,7$ & 937,9 & 948,6 \\
\hline
\end{tabular}

Fuente: Proyecto Rurbano (Estadisticas Especiales).

Sur. Las actividades en el sector no agrario pasan a jugar un papel relevante, ocupando a una proporción cada vez mayor de la población rural sureña que de otro modo inexorablemente habría tenido que emigrar a las ciudades ${ }^{8}$. Así, por ejemplo, mientras que el total de la población rural ocupada ha descendido en casi 1 millón de personas (véase tabla 3) entre los años 1981 y 1997, la proporción de este universo ocupada en actividades ajenas a la agricultura ha pasado del $16,7 \%$ (610,7 mil personas) a aproximadamente el $27,0 \%(763,5$ mil personas), lo que parece indicar que las personas que dejaron la agricultura en esos años encontraron acomodo en otras ocupaciones no agrarias, pero sin abandonar el medio rural.

Observando los datos de la tabla 4 se puede constatar que es en Paraná donde encontramos la tasa más alta de descenso de la población rural ocupada en actividades agrícolas, y la razón para ello tiene que ver con el mayor peso del trabajo asalariado en relación con la agricultura familiar en este Estado federado si se compara con los demás Estados de la región Sur. Esta diferencia puede explicarse por los efectos de la liberalización de las importaciones, que ha significado la desestructuración de importantes sectores generadores de puestos de trabajo asalariado en la agricultura paranaense, como el algodón.

${ }^{8}$ Tal afirmación se ve confirmada en otros estudios llevados a cabo en Brasil, como el desarrollado por Graziano da Silva, Balsadi y Del Grossi (1997:51), que estiman que, al nivel del conjunto de la población rural brasileña, las personas dedicadas al ejercicio de actividades ajenas a la agricultura sumaban 384 mil personas en el año (1996) del estudio. 
Tabla 4.

Evolución del incremento anual de la población activa con edad igual o superior a los diez años en los estados de Rio Grande do Sul (RS), Santa Catarina (SC) y

Paraná (PR) según el lugar de residencia y la situación ocupacional (con los niveles de significación estadistica).

\begin{tabular}{|c|c|c|c|c|c|c|c|}
\hline \multirow[t]{3}{*}{ Situación } & & \multicolumn{6}{|c|}{ Tasas de incremento anual } \\
\hline & & \multicolumn{3}{|c|}{ Período 1981-1992" } & \multicolumn{3}{|c|}{ Periodo $1992-1997^{\mathrm{b}}$} \\
\hline & & RS & $\mathrm{SC}$ & PR & RS & SC & $\mathrm{PR}$ \\
\hline Urbana & & $2,9 * * *$ & $4,5 * * *$ & $3,5 * * *$ & $2,2 * * *$ & $2,7 * * *$ & $2,7 * * *$ \\
\hline Rural & & $-2,0 * * *$ & $-1,0$ & $-2,5 * * *$ & $-0,6^{*}$ & $-0,3$ & $-1,9 * * *$ \\
\hline $\begin{array}{l}\text { Población } \\
\text { rural ocupada }\end{array}$ & Agrícola & $-1,7 * * *$ & 0,4 & $-2,5 * * *$ & $-2,8 * * *$ & $-4,5 * * *$ & $-5,0 * * *$ \\
\hline & No Agrícola & 0,7 & 0,5 & $-0,1$ & 1,7 & $5,6^{* *}$ & $5,8 * * *$ \\
\hline $\begin{array}{l}\text { Población } \\
\text { rural no ocupada }\end{array}$ & Buscando empleo & $4,7^{*}$ & $5,4^{*}$ & $7,9^{* *}$ & $17,8 * * *$ & $15,6^{*}$ & $12,3 * * *$ \\
\hline & Jubilados/pensionistas & $-1,4$ & $-0,1$ & 2,0 & $6,4^{* *}$ & 5,1 & $5,7 * * *$ \\
\hline & Otros & $-4,7^{* * * *}$ & $-5,4 * * *$ & $-4,1 * * *$ & $-0,4$ & $3,4 * * *$ & $-0,8$ \\
\hline
\end{tabular}

(a) El test " $t$ de student" indica si la diferencia es o no significativa.

(b) Estimación de un coeficiente de regresión "log lineal" contra el tiempo. En este caso el test " $t$ " indica la existencia o no de una tendencia en los datos.

$\left({ }^{* *}\right)\left({ }^{* *}\right)$ y $\left({ }^{*}\right)$ indican significación al nivel de $5 \%, 10 \%$ y $20 \%$ respectivamente.

Volviendo a la tabla 3 se observa cómo el número de jubilados que residen en el medio rural ha aumentado espectacularmente, pasando de 255 mil a 335,8 mil personas entre 1981 y 1997 , lo que indica un cambio de tendencia en la salida tradicional de la población rural hacia las ciudades cuando se alcanza la edad de jubilación. La situación en los tres estados de la Región Sur revela un comportamiento análogo en términos de las tasas de incremento anual de los dos colectivos de población rural que estamos analizando. Cobra importancia además el crecimiento de la población desempleada residente en el medio rural en este mismo período, lo que parece demostrar el papel creciente que viene desempeñando el medio rural como colchón de seguridad para la población desfavorecida del campo. Este hecho se enmarca en el actual debate sobre la aludida tendencia hacia la asignación de nuevas funciones al mundo rural. El incremento generalizado de jubilados y pensionistas domiciliados en el medio rural de los tres estados de la Región Sur tiene además que ver con los cambios que introdujo la nueva Carta constitucional (1988), que, entre otras cosas, ampliaba el universo de cobertura y asistencia social de la población residente en el campo, además de establecer criterios de equidad en el tratamiento del trabajador agrícola respecto a las categorías laborales urbanas. 
RIS

REITSTA INTERNACIONAL DE SOCIOLOGIA

Estos hechos tienen importancia en la medida en que ponen de manifiesto un cambio importante en la estructura de oportunidades de la población a la hora de decidir dónde trabajar y dónde situar su lugar de residencia. Los espacios urbanos de las ciudades brasileñas son asociados cada vez más por la opinión pública con el paro, la criminalidad, la congestión de los servicios y las precariedad social y laboral. Por su parte, la opinión pública percibe que el campo ofrece costes de vida más bajos, y permite que muchas de las familias puedan asegurar parte de su subsistencia en la propia explotación familiar, ya sea mediante la puesta en marcha de pequeños cultivos o pequeñas granjas, ya sea a través del desarrollo de la artesanía.

El tercer conjunto de la población rural no ocupada, al que se ha incluido en la categoría de "otros" en la tabla 3 , incluye a las personas que, teniendo $10 \mathrm{o}$ más años de edad en la semana de referencia de la entrevista, no se encontraban buscando empleo y no eran ni jubilados ni pensionistas de la seguridad social, estando en su mayor parte constituido por estudiantes. Para explicar la pérdida de importancia numérica de este grupo de personas que, en 1981, representaba el $25,8 \%$ del total de la población rural de Rio Grande do Sul en edad activa, y en 1997, el 19,6\%, Schneider y Navarro (1998:19-20) formulan algunas explicaciones. Una de ellas sería que tal reducción ha sido provocada por el aumento del número de personas ocupadas en actividades de la economía informal y $\sin$ horarios fijos en términos de jornada laboral, lo que explica que no fueran registradas en la mencionada estadística. Otra explicación es que en esta situación de "otros" se hallarían incluidas las personas mayores que, si bien no perciben una pensión de la seguridad social, permanecen viviendo con sus familias y no son computadas en la estadística. A nosotros nos parece importante pensar también en otras posibilidades. De hecho, en el año 1981 este grupo incluía muchos de los jóvenes que, aunque viviendo en explotaciones agrarias de carácter familiar, no percibían ningún tipo de remuneración económica, de modo que fueron considerados como "no ocupados". Pero tal como hemos visto anteriormente, los años noventa han estado marcados por los efectos del proceso general de envejecimiento de la población rural. En el caso específico de Rio Grande do Sul se ha constatado que el conjunto de personas con edad inferior a los catorce años disminuyó su participación en casi un $6 \%$ en el conjunto de la población, sólo entre los años 1980 y 1991. Habría que realizar nuevos estudios para confirmar estas posibilidades que presentamos para explicar el comportamiento de dicha categoría de la población rural de la Región Sur de Brasil. No obstante, todo indica que la dimensión de este colectivo se ha mantenido prácticamente inalterada entre 1991 y 1997.

Los últimos datos de que disponemos, y que se refieren al año 1997 (tabla 5), permiten además conocer la naturaleza de las nuevas ocupaciones. De hecho, indican que la industria de transformación, la prestación de servicios, el comercio de mercancías y la industria de la construcción son las ramas de actividad no 


\section{Tabla 5.}

Distribución de la población activa rural de Rio Grande do Sul (RS), Santa Catarina (SC), Paraná (PR) y del conjunto de la Región Sur (RSUR) ocupadas en actividades "no agricolas" (en miles de personas) y participación porcentual (\%) según ramas de actividad en 1997.

\begin{tabular}{lrrrrr}
\hline Ramas de actividad & RS & SC & PR & RSUR & $\%$ \\
\hline Industria de Transformación & 90,1 & 93,9 & 64,0 & 248,0 & 32,5 \\
Industria de la Construcción & 34,1 & 20,4 & 20,3 & 74,8 & 9,8 \\
Otras Actividades Industriales & 10,4 & 6,8 & 4,3 & 21,5 & 2,8 \\
Comercio de Mercancias & 33,4 & 18,1 & 27,0 & 78,5 & 10,3 \\
Prestación de Servicios & 83,1 & 39,0 & 67,0 & 189,1 & 24,8 \\
Servicio Auxiliar de Actividades Económicas & 8,4 & 3,4 & 4,0 & 15,8 & 2,1 \\
Transporte y Comunicación & 11,5 & 7,9 & 9,0 & 28,4 & 3,7 \\
Social & 33,0 & 11,9 & 22,0 & 66,9 & 8,8 \\
Administración Pública & 16,7 & 8,5 & 8,0 & 33,2 & 4,4 \\
Otras Actividades & 3,5 & 3,4 & $\mathrm{~s} / \mathrm{inf}$ & $\mathrm{s} / \mathrm{inf}$ & $\mathrm{s} / \mathrm{inf}$ \\
Total & 324,2 & 213,3 & 225,6 & 763,1 & 100,0 \\
\end{tabular}

(s/inf.): sin información. Fuente: Proyecto Rurbano (Estadísticas Especiales).

agrícola que más importancia asumen en el medio rural de la Región Sur, siendo respectivamente responsables de la ocupación del $32,5 \%, 24,8 \%, 10,3 \%$ y $9,8 \%$ de las 763 mil personas económicamente activas residentes en el medio rural de esta parte de Brasil. Muchas de ellas, como por ejemplo la prestación de servicios técnicos o la propia industria de la transformación, tienen estrecha relación con la agricultura, mientras que nuevas iniciativas vinculadas al turismo rural, a los pequeños talleres artesanales o a los servicios personales, empiezan a ganar creciente importancia en la ocupación de la fuerza de trabajo, si bien las estadísticas disponibles no permiten captar con precisión su verdadera dimensión.

Hasta hoy, el alcance e incidencia de la pluriactividad en el medio rural de la Región Sur de Brasil sólo pueden ser valorados desde el punto de vista de estudios realizados a nivel local o desde la perspectiva de las estadísticas demográficas y laborales. En efecto, el último Censo agrícola (1995-96) que se realiza cada diez años, no permite todavía captar ni la naturaleza y dimensión de las rentas no agrícolas, ni tampoco las características de estas ocupaciones y actividades desarrolladas por el conjunto de los miembros de las familias rurales, tanto dentro, como fuera de la propia explotación. De hecho, con base en la fuente más actualizada de información (PNAD) es posible llegar a una aproximación tomando como base la "familia rural extensa", que se considera 
RIS

REIISTA INTERNACIONAL DE SOCIOLOGIA

N" 28. Enero-Abril. 2001

FLAVIO SACCO DOS ANJOS

como unidad pertinente de análisis desde el punto de vista del ya mencionado Proyecto Rurbano y que es definida como "el conjunto de personas que constituyen un agregado familiar (la familia nuclear y sus parientes) y residen en los domicilios particulares permanentes" recogidos en la investigación.

Con base en estos criterios se establecen cinco grandes categorías de familias extensas: 1) familias de empleadores que contratan hasta dos trabajadores permanentes, 2) familias de empleadores que contratan más de dos trabajadores permanentes, 3) familias de trabajadores por cuenta propia, 4) familias de trabajadores ocupados y 5) familias de desocupados y no ocupados (que declararon no haber ejercido trabajo en la semana de referencia de la entrevista, comprendiendo esencialmente las familias de jubilados, pensionistas y desempleados).

Todos los tipos de familias, residentes en el medio urbano o rural, exceptuando la categoría de "desocupados", fueron clasificados también como familias agrícolas, familias no agrícolas y familias pluriactivas. Las "familias agrícolas" son aquéllas en las que todas las personas de la familia extensa estaban ocupadas exclusivamente en actividades agroganaderas en la semana de referencia de la PNAD, teniendo en cuenta tanto la ocupación principal, como las ocupaciones secundarias de sus miembros. Las "familias no agrícolas" se refieren a la situación exactamente contraria a las agrícolas. Finalmente, las "familias pluriactivas" son las que, al menos, uno de los miembros activos de la familia extensa declaró haber ejercido actividades no agrícolas, sea como actividad principal, sea como secundaria. Hechas estas aclaraciones conceptuales, examinemos los datos disponibles.

A través de los datos de la tabla 6 se constata que, de las 1.383 .000 familias extensas existentes en la Región Sur el año 1997, tan sólo el 1,6\% de ellas son familias de "empleadores con más de dos empleados". En esta categoría llama la atención la escasa presencia en ella de las familias exclusivamente agrícolas $(26,7 \%)$ y la alta proporción de familias pluriactivas $(17,1 \%)$ y de las no agrícolas $(56,2 \%)$.

En los últimos cinco años se viene constatando el incremento de los grupos domésticos que optan por vivir en el campo o que deciden establecer su segunda vivienda en casas particulares o condominios horizontales. Este hecho, como es de suponer, engendra otros efectos, de los que llamamos la atención la ampliación de oportunidades de empleo y trabajo para la población rural, especialmente en la esfera de los servicios domésticos y personales. Las familias de "empleadores con hasta dos empleados" representa el 4,2\% del total de las familias extensas de la Región Sur de Brasil y la participación de la categoría exclusivamente agrícola es muy superior al grupo anterior, ascendiendo al 62,0\%. Las familias "por cuenta propia" comprenden esencialmente el universo de las explotaciones familiares. Es el grupo más numeroso y comprende el 53,4\% del total de familias extensas del Sur de Brasil. 
Como se puede observar también en la tabla 6, aproximadamente el $71 \%$ de ellas son exclusivamente agrícolas, mientras que casi el $18 \%$ son de tipo pluriactivas y el $11,3 \%$ son no agrícolas en exclusivo. Al fin y al cabo lo que estos datos muestran es que en casi el $30 \%$ de las familias rurales extensas de tipo cuenta propia la agricultura no corresponde a la actividad más importante $o$ exclusiva desde el punto de vista de la ocupación de las personas.

El segundo gran grupo de familias numéricamente más expręsivo es el de la de "trabajadores ocupados", que acapara cerca de la tercera parte del total de familias extensas de la Región Sur de Brasil. En esta condición llama la atención el hecho de que tan sólo el $37,0 \%$ está representado por familias agrícolas en exclusivo, mientras que el $14,9 \%$ son de tipo pluriactivo y el $48,1 \%$ son clasificadas como no agrícolas. Este hecho tiene que ver con las nuevas oportunidades abiertas con la urbanización del medio rural protagonizada tras la

Tabla 6.

Distribución de las familias rurales extensas (en miles de familias) existentes en los estados de Rio Grande do Sul (RS), Santa Catarina (SC), Paraná (PR) y en el conjunto de la Región Sur (RSUR) y respectiva participación porcentual (\%) según la categoría ocupacional en el año 1997.

\begin{tabular}{lrrrrr}
\hline Tipo de familia & RS & SC & PR & RSUR & $\%^{*}$ \\
\hline Empleador de más de 2 empleados & 12,7 & 4,0 & 5,0 & 21,7 & 1,6 \\
Agrícola & 3,8 & 1,0 & 1,0 & 5,8 & 26,7 \\
Pluriactiva & 1,7 & 0,0 & 2,0 & 3,7 & 17,1 \\
No Agrícola & 7,2 & 3,0 & 2,0 & 12,2 & 56,2 \\
Empleador de hasta 2 empleados & 26,2 & 13,5 & 19,0 & 58,7 & 4,2 \\
Agrícola & 16,4 & 9,0 & 11,0 & 36,4 & 62,0 \\
Pluriactiva & 5,8 & 2,0 & 6,0 & 13,8 & 23,5 \\
No Agrícola & 4,0 & 2,5 & 2,0 & 8,5 & 14,5 \\
Por cuenta propia & 309,5 & 179,5 & 250,0 & 738,5 & 53,4 \\
Agrícola & 207,4 & 131,5 & 184,0 & 522,9 & 70,8 \\
Pluriactiva & 62,4 & 25,0 & 45,0 & 132,4 & 17,9 \\
No Agricola & 39,7 & 22,0 & 21,0 & 82,7 & 11,3 \\
Trabajadores Ocupados & 162,6 & 117,0 & 178,0 & 457,6 & 33,2 \\
Agrícola & 52,2 & 35,0 & 82,0 & 169,2 & 37,0 \\
Pluriactiva & 27,1 & 13,0 & 28,0 & 68,1 & 14,9 \\
No Agrícola & 83,3 & 69,0 & 68,0 & 220,3 & 48,1 \\
Desocupados & 48,3 & 21,5 & 36,0 & 105,8 & 7,6 \\
Total & 559,3 & 335,5 & 488,0 & $1.382,8$ & 100,0 \\
\hline
\end{tabular}

(*) Los porcentajes expresan la distribución en el conjunto de las categorias de la Región Sur de Brasil y según los subtipos en el interior de cada categoría (agrícola, pluriactiva y no agrícola). 
RIS

RETISTA INTERNACIONAL DE SOCIOLOCIA

N" 20. Enero-Abril. 2001

FLAFIO SACCO DOS ANJOS

sensible mejora de las comunicaciones y fundamentalmente con la cuestión que subrayamos anteriormente referente a los nuevos usos de los espacios rurales. En efecto, se puede además observar en la tabla 6 que, bajo la condición de "desocupados" (pensionistas, jubilados y desempleados temporales), se hallan incluidos una proporción correspondiente al 7,6\% del total de familias rurales extensas, cifra que supera incluso la suma de las dos categorías de familias de empleadores (con más de dos empleados y con hasta dos empleados).

\section{PLURIACTIVIDAD Y POLÍTICA DE DESARROLLO RURAL}

La importancia de la pluriactividad no reside simplemente en su peculiar condición, como manifestación resultante del proceso de ajuste y adaptación de la agricultura de base familiar, sino porque representa la plasmación objetiva de una gran ruptura en los viejos esquemas y planteamientos políticos radicados en una visión dicotómica de la realidad social que convirtió el mundo rural, sobre todo desde el punto de vista de los países en vías de desarrollo, en algo intrascendente y desprovisto de cualquier significado, bajo la égida de la sociedad urbana e industrial. Ha tenido un efecto altamente negativo el proyecto global de desarrollo llevado a cabo en Brasil desde la segunda mitad de los años sesenta y radicado fundamentalmente en el "productivismo a ultranza".

Bajo la égida de los esquemas dualistas-difusionistas, Brasil ha estado sometido a un modelo cuya característica esencial reside en lo que define la tipología propuesta por Biswanger (1994) como de "expulsión prematura de trabajo" (EPT). De hecho, el llamado patrón EPT (Veiga, 1997:4) se asienta sobre todo en el acentuado sesgo urbano en la asignación de recursos y en una total subordinación de la agricultura y del mundo rural al papel de financiar y sostener los procesos de expansión urbana e industrial, considerados entonces como sinónimos inequívocos de desarrollo. Aunque el patrón EPT ha engendrado unos efectos perversos de gran envergadura, no han sido suficientes para erradicar la agricultura familiar, un tipo de producción que es la base esencial y estratégica del modelo reductor de la pobreza (RP) de objetivos antagónicos al patrón EPT. Desde esta perspectiva, se trata de buscar un modelo de desarrollo equilibrado en sus distintas dimensiones (social, territorial, económica y política) que integre el medio rural en las políticas públicas y que rompa definitivamente con muchos de los vicios del pasado.

El caso de Brasil es indiscutiblemente emblemático para describir la trayectoria de una sociedad cuyas élites del poder siempre han preferido, bajo la égida del patrón EPT, tener muchos obreros en el campo y en la periferia de las ciudades y en empleos muy precarios, en lugar de fomentar la consolidación de una clase media significativa y un amplio universo de agricultores. No causa extrañeza a ningún observador de la realidad brasileña el hecho de que las 
regiones que desde los últimos años han presentado de modo recurrente los más altos índices de desarrollo humano, según los criterios del Programa de las Naciones Unidas (véase PNUD/IPEA en sus dos ediciones: 1996 y 1998), sean justamente regiones caracterizadas por la presencia mayoritaria de la agricultura familiar como forma social de producción. A lo largo de nuestra exposición hemos subrayado insistentemente acerca de ello, tanto en el momento de describir los rasgos de la realidad social, económica y cultural del Sur del país, como en el instante en que caracterizamos las formas en que se manifiesta la pluriactividad en dicha región.

El creciente desencanto hacia las formas de vida de la sociedad urbana (con su corolario de inseguridad ciudadana y hacinamiento), el problema del paro, el desequilibrio territorial y el agotamiento de los recursos naturales no renovables, son parte del caldo de cultivo que ha conducido a que distintos sectores de la opinión pública y de la clase política estén volviendo a interesarse por los espacios rurales. En el caso específico de Brasil, dicha reflexión apenas ha empezado, si bien es ya un hecho que el desarrollo rural se está convirtiendo en un tema muy importante en las agendas públicas y en la comunidad científica, en su esfuerzo por encontrar soluciones a los problemas de la sociedad brasileña en unos tiempos como éstos de comienzo de milenio en los que se produce una profunda reestructuración del sistema capitalista a nivel mundial.

El nuevo escenario que se presenta en Brasil pone de manifiesto que, junto a la vigencia de viejas cuestiones que aún siguen pendientes (como la reforma agraria o los desequilibrios interregionales), surgen otras nuevas (como el desempleo tecnológico o los efectos de la creciente liberalización de los mercados) que exponen a la economía brasileña a la competencia internacional en un contexto marcado además por la hegemonía de políticas neoliberales que abogan por la retirada de Estado de áreas importantes de la actividad productiva y sensibles desde el punto de vista social. En este contexto cobra mayor importancia si cabe el "Programa Nacional de Fortalecimiento de la Agricultura Familiar" (PRONAF) recientemente aprobado por el Gobierno brasileño, como reflejo de nuevas orientaciones en favor de una acción política descentralizada y con un fuerte contenido democrático en su forma de implantación y gestión. Aunque no puede hacerse todavía un balance del mismo, se aboga por que se convierta en una herramienta estratégica de potenciación del desarrollo agrícola y rural, que esté en sintonía con otras iniciativas que favorezcan la formación de un tejido productivo más diversificado al nivel de los pequeños municipios brasileños.

Si se pretende impulsar la consolidación de un medio rural diversificado y activo, habría que pensar en la necesaria articulación de las políticas públicas como motor de esta dinámica, recuperando el protagonismo de la intervención estatal de acuerdo con estos nuevos planteamientos. Cada vez más se extiende entre la opinión pública y la comunidad política brasileña la necesidad de que 
la búsqueda de soluciones a los problemas del país se plantee superando la vieja separación rural-urbana que ha marcado el debate sobre los modelos de desarrollo. En esta nueva forma de reflexionar sobre el futuro del mundo rural brasileño se aboga por que la necesaria industrialización de estas zonas no signifique inevitablemente su des-ruralización y por que la política pública contribuya al logro de un adecuado equilibrio social y demográfico en ellas. En el marco de esos debates, la pluriactividad cobra una dimensión nueva, valorándose positivamente su capacidad para impulsar la articulación entre agricultura y otros sectores de actividad, contribuyendo a la fijación de población en el medio rural y a la permanencia de un sector dinámico de explotaciones de tipo familiar.

Para valorar la magnitud de este debate baste recordar el dato de que en Brasil hay una población de 34 millones de personas viviendo en zonas rurales (5,4 millones si nos referimos a la Región Sur), lo que representa un potencial indiscutible que debe ser aprovechado como parte activa de la sociedad. Pero lo importante de cómo se desarrollan estos nuevos debates sobre el futuro del mundo rural brasileño, y que este artículo ha pretendido mostrar, es que, a diferencia de los anteriores, en los de ahora se aboga por evitar que la inevitable y necesaria modernización de la agricultura convierta a la población agrícola y rural en clientela de políticas asistencialistas guiadas por planteamientos arcaicos que no tengan en cuenta los cambios que se están produciendo en los ámbitos económicos, culturales y políticos a nivel mundial. No es volver a la idea del viejo corporativismo agrario de que la agricultura es el vector esencial de la sociedad y el motor del desarrollo económico, sino de definir un nuevo discurso (no esencialista) sobre la ruralidad; un discurso que, basado en el nuevo paradigma de la multifuncionalidad, valore la contribución de la población agrícola a la preservación de los recursos naturales y la importancia de la diversificación de actividades como salida a la destrucción masiva de empleo provocada por la crisis de determinados sectores productivos cuando todavía no se perciben los efectos positivos que los especialistas atribuyen a la llamada "nueva economía".

\section{CONCLUSIONES}

En este artículo hemos centrado nuestro esfuerzo interpretativo en tratar de identificar cómo han cambiado la agricultura y el mundo rural de la región agrícola más importante de Brasil, la Región Sur. Nuestra atención se ha centrado fundamentalmente en el tema de la pluriactividad, en el sentido de mostrar los factores y circunstancias que determinan y/o favorecen su emergencia y consolidación en cuanto fenómeno social y económico cuya creciente importancia parece indiscutible a la luz de los estudios realizados 


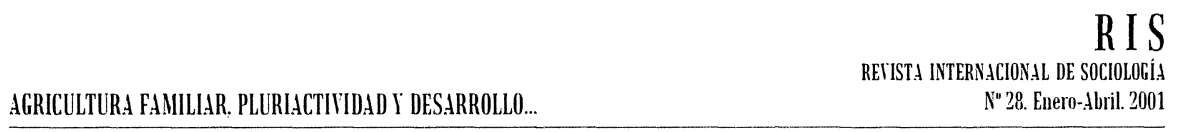

recientemente. Sin embargo, tal como hemos intentado mostrar, su emergencia responde a unas características y unos rasgos estructurales que no pueden ser extendidos a otras regiones brasileñas, debido a la profunda reestructuración que experimentan las explotaciones familiares de la Región Sur y a su fuerte protagonismo en el escenario nacional, tanto en el ámbito del sistema agroalimentario brasileño y de los mercados internos, como en el de las exportaciones agrarias. A ello habría que añadir la singularidad que representa respecto a otras regiones brasileñas el peso de la formación social y cultural de las colonias europeas en la Región Sur, que, como hemos señalado, ha jugado un papel fundamental tanto en la estructuración de la forma familiar de producción en esta región, como en el impulso que ha supuesto para la implantación de un modelo de desarrollo industrial de carácter diversificado y flexible, muy diferente a la del sudeste brasileño liderado por el Estado de São Paulo. Sectores muy importantes de la economía sureña, como el textil y el calzado, vienen siendo identificados por los analistas como ejemplos de industrialización difusa siguiendo el llamado modelo NEC o "Tercera Italia". De hecho, la complementariedad establecida entre el proceso de reproducción material de las familias rurales de los descendientes de inmigrantes y las estrategias de expansión industrial, parecen inexorablemente vinculados y mútuamente convergentes bajo la clásica situación del obrero campesino.

Asimismo, hay que destacar que el entorno económico en el que se halla inmersa la agricultura familiar de la Región Sur le ha impuesto dificultades crecientes en el marco de las posibilidades que brinda la actividad agraria, tanto en cuanto fuente de ingreso para la reproducción material de estas explotaciones, como en el ámbito de la ocupación de la fuerza de trabajo de los grupos domésticos. En este sentido entendemos que el proceso que se desarrolla en esta región de Brasil sigue unas pautas y líneas de evolución consonantes con la trayectoria experimentada en los países centrales y semiperiféricos, en los que tanto el descenso de la población activa ocupada en la agricultura, como la participación de este sector en la economía general muestran una tendencia a la baja.

No obstante, no hay que olvidar que el carácter excluyente y conservador de la modernización agraria brasileña no ha hecho más que reforzar dicha tendencia en la medida que no ha favorecido unas condiciones mínimas y aceptables para favorecer dicha forma de producción. Además de impulsar un éxodo rural sin precedentes, la modernización ha engendrado grandes desequilibrios demográficos en los que destaca el proceso de envejecimiento de la población rural. El panorama se completa bajo la creciente importancia que juegan los efectos de la globalización de la economía y del proceso de integración regional (Mercosur), que decididamente vienen en perjuicio de las explotaciones familiares económicamente más débiles aunque hayan incorporado masivamente las innovaciones tecnológicas. 
Desde nuestro punto de vista es imposible comprender los cambios que tienen lugar en la Región Sur fuera de este marco general. La tesis de este artículo es que el fenómeno de la pluriactividad, surgido hasta ahora de forma espontánea como respuesta de las familias rurales al nuevo contexto de cambio, puede integrarse en el nuevo discurso sobre la ruralidad a condición de que se formule en términos de una estrategia impulsada por los poderes públicos (estatales o federales) que permita incorporar dicho fenómeno en el marco de las nuevas políticas agrarias. En este sentido coincidimos con autores que proponen una reformulación de la aún pendiente cuestión agraria brasileña, que vaya más allá de la vieja idea del simple reparto de tierras circunscrito al estricto marco de la agricultura (Graziano da Silva,1996). Bajo este enfoque lo que se plantea es el objetivo de transformar los nuevos asentamientos del MST (Movimiento de los Sin Tierra), cuyo número se multiplica en los últimos tiempos a causa de la presión popular y del protagonismo de los movimientos sociales, en espacios rurales de producción en el sentido más amplio de la palabra, unos espacios donde además de explotar los recursos agrícolas con criterios sostenibles se favorezca la diversificación de actividades y rentas, es decir, la pluriactividad. Hay ya experiencias exitosas en esta línea ${ }^{9}$.

Aunque de modo indirecto, este estudio pretende incidir en este debate. No obstante, entendemos también que la pluriactividad no puede ser tomada como panacea que vaya a resolver los grandes problemas que atraviesa el medio rural brasileño. Pero junto a las enormes y diversificadas demandas de la población, habría que tener en cuenta todas las ventajas y posibilidades que podría brindar esta modalidad de organización de la agricultura familiar. Si nuestras consideraciones contribuyen a que ocurra dicha reflexión, daremos por cumplidos algunos de los objetivos que nos habíamos marcado.

\footnotetext{
"Véase el informe producido por la Secretaria de Agricultura del Gobierno de Brasilia relativo al proyecto titulado: "Prove o gosto da inclusão social". En un artículo publicado en el periódico $O$ Estado de São Paulo ("Sem-terra começam a se interessar pela criação de frangos") dicha iniciativa es presentada como una experiencia exitosa, desarrollada en municipios como Cristalina, en el Estado brasileño de Goiás, y que persigue los mismos objetivos. No se trata simplemente de buscar una nueva forma de potenciar la inserción de los productores asentados en nuevos y diferenciados mercados locales, sino que se echa mano de una estrategia con un fuerte contenido ético, que reafirma la importancia de apoyar la Reforma Agraria desde una perspectiva novedosa, democrática y participativa.
} 


\section{REFERENCIAS BIBLIOGRÁFICAS}

ARNALTE ALEGRE, E. (1980), "Agricultura a tiempo parcial y transformaciones del campesinado", Agricultura y Sociedad, n 17, Madrid, MAPA, octubre/diciembre, pp. 203-223

BELIK, W. (1997), "Changing Patterns of State Intervention in the Brazilian Agro-industrial Complex", Sociologia Ruralis, vol. 37, n³, Assen (Paises Bajos), diciembre, pp. 405-424.

BISWANGER, H. P. (1994) "Agricultural and Rural Development: Painful Lessons. Revised version of the Simon Brandt", ponencia presentada al 32nd Annual Meeting of the Agricultural Economics Association of South Africa, Pretoria, Sudáfrica (mimeo).

BRASIL, Instituto Brasileiro de Geografia e Estatística, IBGE (1994), Censo Demográfico 1991 Resultados do universo relativos às características da população e dos domicilios en los Estados de Rio Grande do Sul, Santa Catarina y Paraná, Rio de Janeiro, Brasil.

(1995), Anuário Estatístico 1995, Río de Janeiro, Brasil.

(1997), Censo Agropecuário - 1995/1996, n²1, Santa Catarina, Río de Janeiro, Brasil.

(1998) Censo Agropecuário - 1995/1996. n²0, Paraná, R. de Janeiro, Brasil.

(1998), Censo Agropecuário - 1995/1996. n²2, Rio Grande do Sul, Rio de Janeiro, Brasil.

BRUM, A. (1987), O Desenvolvimento Econômico Brasileiro, $8^{\mathrm{a}}$ ed, Rio de Janeiro, Vozes, $220 \mathrm{p}$.

CAVAZZANI, A. y A. FÜLLER (1982), "International perspectives on part-time farming: a review", GeoJournal, vol 6, nº 4, pp. 383-89.

COULOMB, P. y H. NALLET (1980), Le syndicalisme agricole et la creation du paysan modéle, París, INRA.

DE JANVRY, A., E. SADOULET y L. WILCOX YOUNG (1989), "Land and labour in Latin American agriculture from the 1950s to the 1980", The Journal of Peasant Studies, vol. $16, \mathrm{n}^{\circ} 3$.

DELGADO, G. (1985), Capital financeiro e agricultura no Brasil: 1965-1985, São Paulo/Campinas, Ícone/Editora de la Unicamp.

DELORME, H. y F. Le THEULE (1996): "Réforme de la PAC et Uruguay Round: vers une Europe libérale" en M. Jollivet et N. Eizner (eds.), L'Europe et ses campagnes, Presses de Sciences Politiques, Paris, pp. 275-294.

ETXEZARRETA, M., J. CRUZ, M. GARCÍA MORILLA y L. VILADOMIU (1995), La agricultura familiar ante las nuevas politicas agrarias comunitarias, Madrid, MAPA, Serie Estudios.

FAO/INCRA (1996), Perfil da agricultura familiar no Brasil: dossiê estatistico. Projeto UFT/BRA/ 036/BRA, Agosto. Brasília, Incra, 25 pág. 
FRANKLIN. H. (1969), The European Peasantry: The Final Phase, Londres, Methuen.

FÜLLER, A. M. (1984), "Part-Time Farming: the enigmas and the realites", en H. Schwarzweller (ed.) Research in Rural Sociology and Development, Connecticut, Jai Press.

(1990) "From Part-time farming to Pluriactivity: a decade of change in rural Europe", Journal of Rural Studies, vol. 6, n 4, Gran Bretaña, pp.361-373.

GAIGER, I. (1994), "A práxis coletiva dos sem-terra rumo à unidade ou à heterogeneidade cultural?", Cadernos de Sociologia, n 6, Porto Alegre, IFCH/Ufrgs, pp. 177-203.

GRAZIANO DA SILVA, J. (1982), A modernização dolorosa: Estrutura agrária, fronteira agrícola e trabalhadores rurais no Brasil, Rio de Janeiro, Zahar Editores.

(1983), O que é Questão Agrária? 14ª ed. Sao Paulo, Brasiliense (Coleção Primeiros Passos).

(1996), "Por uma Reforma Agrária não essencialmente agrícola", Revista Agroanalysis, Marzo, vol. 16, nº 3, pp. 8-11, Rio de Janeiro.

GRAZIANO DA SILVA, J., O.V. BALSADI, M.E. DEL GROSSI (1997), "O Emprego Rural e a Mercantilização do Espaço Agrário", São Paulo em Perspectiva, São Paulo, Fundação SEADE, vol.11, n², abril-junio, pp. 50-64.

GUIMARÃES, A. P. (1979), A Crise Agrária. Rio de Janeiro, Paz e Terra (Coleção O Mundo, Hoje, vol. 29).

HERVIEU, B. (1996), Los Campos del Futuro, Madrid, MAPA, Serie Estudios (1 ${ }^{\text {a }}$ edición en francés, Edit. F. Boulin, 1993).

KAY, C. (1995), "Desarrollo rural y cuestiones agrarias en la América Latina contemporánea", Agricultura y Sociedad, n 75, Madrid, MAPA, abril/junio, pp. 27-82.

KLEIN, E. (1992), "El Empleo Rural no Agrícola en América Latina", Documento de Trabalho, $\mathrm{n}^{\circ}$ 364, OIT/PREALC/CEPAL, Santiago de Chile.

KOLANKIEWICZ, G. (1979), "Una nueva clase incómoda: el campesino a tiempo parcial en Polonia", Agricultura y Sociedad, n 13, octubre/diciembre, Madrid, MAPA, pp. 65-111.

LAGRAVE, R.M. (1993), "El COPA, o la representación de la representación”, en E. Moyano (coord.), Las organizaciones profesionales agrarias en la Comunidad Europea, Madrid, MAPA, Serie Estudios.

MARTINE, G. A. (1987), "Efeitos Esperados e Imprevistos da Modernização Agrícola no Brasil", en G. Martine y R. Coutinho Garcia (coord.), Os Impactos Sociais da Modernização Agrícola, Sao Paulo, Caetés.

MOYANO ESTRADA, E. (1988), Sindicalismo y politica agraria en Europa. Las organizaciones profesionales agraras en Francia, Italia y Portıgal, Madrid, MAPA, Serie Estudios. 
MOYANO ESTRADA, E. (coord.) (1993), Las organzaciones profesionales agrarias en la Comunidad Europea, Madrid, MAPA, Serie Estudios.

(1997) (coord.), Por un cambio necesario en la agricultura europea, Grupo de Brugge (Brujas)/MAPA, Madrid.

NAREDO, J. M. (1971/1996), La Evolución de la Agricultura en España (1940-1990), Granada, Universidad de Granada.

OLIVEIRA, A. U. (1994), "O Campo brasileiro no final dos anos 80", en J.P. Stédile (coord), $A$ Questão Agrária Hoje, Porto Alegre, Ed. da UFRGS, pp. 45-67.

ORTEGA, E. (1992), "Evolution of the rural dimensión in Latin America and the Caribbean", en CEPAL Review, $\mathrm{n}^{\circ} 47$.

PALAU VILADESAU, T. y M.V. HEIKEL (1987), "Los actores sociales en el campo: un intento de identificación", en Los campesinos, el Estado y las empresas en la frontera agrícola, Asunción, BASE/PISPAL, pp 129-176.

PIÑEIRO, D. (1985), Forma de resistencia de la agricultura familiar: el caso del Noreste de Canelones, Montevideo, CIESU.

PNUD/IPEA. (1996), Programa das Nações Unidas para o Desenvolvimento - PNUD / Instituto de Pesquisa Econômica Aplicada - IPEA. Relatório sobre o desenvolvimento humano no Brasil, Rio de Janeiro, IPEA, Brasília, DF/PNUD.

RAUD, C. (1995a), "Santa Catarina: un exemple d'industrialisation décentralisée au Brésil", Notes de Recherche, Paris, CRIA, vol. 52.

(1995b), "Potencial e Modalidades da industrialização difusa no Brasil", GEOSUL, n 19/20, año $\mathrm{X}, 1^{\circ}$ e $2^{\circ}$ Semestres, pp. 76-101.

(1999), Indístria, território e meio ambiente no Brasil. Perspectivas da industrialização descentralizada a partir de análise da experiência catarinense, Florianópolis, Ed. da UFSC; Blumenau, Ed. da FURB.

RYFF, T. (1988), "Diagnóstico Regional - Regiōes Sul e Sudeste", en M. Aguiar y M. De N. (coord.), A Questão da Produção e do Abastecimento Alimentar no Brasil: um diagnóstico Macro com Portes Regionais, Brasília, IPEA/IPLAN, PNUD; Agência Brasileira de Cooperação, pp. 61-135.

SACCO DOS ANJOS, F. (1994), "A Agricultura Familiar em Transformação: o surgimento dos part time farmer's em Santa Catarina", Anais do XXXII Congresso Brasileiro de Economia e Sociologia Rural, vol. I, Brasília, SOBER, pp. 442-449.

(1995a), A Agricultura Familiar em transformação: $O$ caso dos colonos-operários de Massaranduba, Santa Catarina, Pelotas, Editora da UFPEL. 
(1995b), "Imprecisões, Ambigüidades e Contradições. Das Sociologias do "Rural" às fronteiras imprecisas entre o Rural e o Urbano", Anais do XXXIII Congresso Brasileiro de Economia e Sociologia Rural, vol. 2, Brasilia, SOBER, pp. 1196-1207.

(1995c), "Colonos ou Operários: Quem vai ficar na terra?", Universidade e Sociedade, Año $5, n^{\circ} 8$, Brasilia, pp. 38-44.

SACCO DOS ANJOS, F. y E. MOYANO ESTRADA (2001), "The new forms of economic cooperation in family agriculture. The case of Condominios in Santa Catarina, Brazil", The Journal of Rural Cooperation, 29 (1), pp. 25-45, Jerusalén.

SACHS, I. (1990), "Desarrollo sustentable, bio-industrialización descentralizada y nuevas configuraciones rural-urbanas. Los casos de India y Brasil", Pensamiento Iberoamericano, Madrid, vol. 16, pp. 235-256.

SCHNEIDER, S. (1994), Os colonos da indístria calçadista: expansão industrial e as transformações da agricultura familiar no Rio Grande do Sul, Campinas, IFCH/UNICAMP (Tesis de Mestrado).

(1995), "As Transformações Recentes da Agricultura Familiar no Rio Grande do Sul: o caso da agricultura em tempo parcial", Ensaios FEE, Porto Alegre, vol. 16, n 1, pp.105-129.

(1999a), Agricultura familiar e industrialização: Pluriatividade e descentralização industrial no Rio Grande do Sul, Porto Alegre, Ed. Universidade/UFRGS.

(1999b), Agricultura familiar e pluriatividade, Porto Alegre, PPGS/UFRGS (Tesis de Doctorado).

SCHNEIDER, S. y Z. NAVARRO (1998), "Agricultura e Novas Formas de Ocupação no Meio Rural (um estudo de tendências recentes)", Anais do XXXVI Congresso Brasileiro de Economia e Sociologia Rural, vol. 2, Brasília, SOBER, pp. 617-635.

SERVOLIN, C. (1972), "L'absorption de l'agriculture familiale dans le mode de production capitaliste", en Y. Tavernier et al (eds), L'univers politique des paysans dans la France contemporaine, FNSP y Ed. Armand Colin, Paris, pp. 41-78.

SEYFERTH, G. (1974), A Colonização Alemã no Vale do Itajai-Mirim: um estudo de desenvolvimento econômico, Porto Alegre, Movimento (Coleção Documentos Brasileiros).

(1985), "Herança e Estrutura Familiar Camponesa", Boletim do Museu Nacional, N.S. Antropologia, n. 52.

(1987), "Aspectos da Proletarizaçào do Campesinato no Vale do Itajaí (SC): os colonosoperários", en J.S.L. Lopes (coord.) Cultura \& Identidade Operária: aspectos da cultura da classe trabalhadora, Rio de Janeiro, Sao Paulo, UFRJ, PROED, pp.103-120.

TEDESCO, J.C. (1999), “Contratualização e racionalidade familiar”, en J.C. Tedesco (coord.), Agricultura familiar: realidades e perspectivas, Passo Fundo, EDIUPF, pp. 107-145. 
RIS

RETISTA INTERNACIONAL DE SOCIOLOGIA

AGRICULTURA FAMILIAR. PLURIACTIVIDAD Y DESARROLLO... N" 28. Enero-Aluil. 2001

VEIGA, J. E. (1997) “Uma Estratégia de Desenvolvimento Rural para o Brasil"; en XXI Encontro Anual da ANPOCS (mimeo).

WELLER, J. (1997) "El Empleo Rural no Agropecuario en el Istmo Centroamericano", Revista de la CEPAL, Chile, $\mathrm{n}^{\circ}$ 62, agosto, pp. 75-90. 